Nota de investigación

\title{
Análisis morfométrico de harina, almidón y proteína de Tropaeolum tuberosum Ruiz and Pavón
}

\author{
Deysi Guevara-Freire ${ }^{1 \S}$ \\ Diana Coello-Fiallos ${ }^{2}$
}

${ }^{1}$ Facultad de Ciencias Agropecuarias-Campus Querochaca-Universidad Técnica de Ambato. Carretera Cevallos-Quero, Tungurahua, Ecuador. CP. 180602. Tel. 59 32580191. ${ }^{2}$ Grupo de Ciencia y Tecnología de Materiales-Facultad de Ingeniería Civil y Mecánica-Campus Huachi Chico-Universidad Técnica de Ambato. Av. Los Chasquis y Río Payamino, Ambato, Ecuador. CP. 180207. Tel. 5930328411. (jc.coello@uta.edu.ec).

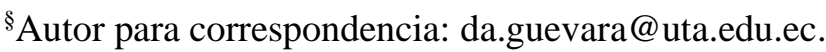

\section{Resumen}

La mashua (Tropaeolum tuberosum Ruiz and Pavón) es un tubérculo comestible y domesticado en la región central de los Andes; de poca importancia comparado con otros cultivos andinos, pero con un gran potencial para ser explotado en la industria. Por tal razón, el objetivo de este estudio fue determinar las características morfológicas del almidón, harina y proteína liofilizada de cuatro genotipos de mashua cultivadas en el herbario de la Facultad de Ciencias Agropecuarias en 2018. Mediante el uso del microscopio electrónico de barrido (MEB), los resultados mostraron gránulos de harina con formas esféricas, ovaladas con diámetro mayor y menor de $6 \mu \mathrm{m}$ y $5 \mu \mathrm{m}$ en el genotipo amarilla (MA); $9.4 \mu \mathrm{m}$ y $8.6 \mu \mathrm{m}$ en el genotipo blanco (MB), $8.3 \mu \mathrm{m}$ y 6.9 en el genotipo verde amarilla (MVA), $9.9 \mu \mathrm{m}$ y $9.1 \mu \mathrm{m}$ en el genotipo poza rondador (MPR). Los gránulos de almidón tienen tamaños de $7.1 \mu \mathrm{m}$ y $6.1 \mu \mathrm{m}$ (MA), $18 \mu \mathrm{m}$ y $16.3 \mu \mathrm{m}(\mathrm{MB}), 8.3 \mu \mathrm{m}$ y $7.3 \mu \mathrm{m}$ (MVA), $7 \mu \mathrm{m}$ y $6.5 \mu \mathrm{m}$ (MPR) con formas esféricas, ovaladas y esféricas-truncadas. Mientras que las micrografías de la proteína liofilizada se observó láminas con tamaños de 130, 221, 224 y 237 $\mu \mathrm{m}$ (MVA, MA, MB y MPR, respectivamente). La forma ovalada y esférica se destacan en los gránulos de harina y almidón y la forma poligonal aplanada en la proteína, mientras que los de mayor tamaño fueron los genotipos MB y MPR (almidón y harina) y en el caso de la proteína MPR.

Palabras clave: andino, forma, gránulo, tamaño.

Recibido: febrero de 2021

Aceptado: marzo de 2021 
En los tiempos precolombinos los pueblos andinos han domesticado alrededor de 70 cultivos en el Ecuador nueve especies han sido estudiadas y un tubérculo de nombre mashua se destaca por sus cualidades nutricionales y medicinales. Tropaeolum tuberosum Ruiz \& Pavón es el nombre científico de esta especie, que se ubica taxonómicamente en la familia Tropaeolaceae, género Tropaeolum (Lim, 2016).

La diversidad genética del tubérculo es variada pero menor comparada con la oca (Oxalis tuberosa) y el olluco (Ullucus tuberosus) (Pissard et al., 2008), entre genotipos se diferencian por su color, forma y sabor (Flores et al., 2003). El tubérculo posee una composición nutricional importante, con altos niveles de ácido ascórbico (vitamina C), riboflavina (vitamina B2), tiamina (vitamina B1) (National Research Council, 1989), elevado contenido de proteína incluso superiores a la papa, oca y olluco (Manrique et al., 2013), fibra (Flores et al., 2003) y alto contenido de caroteno (Barrera $e t$ al., 2004).

Los usos de la mashua son variados se destaca en preparaciones culinarias (Barrera et al., 2004) y medicina tradicional por sus compuestos bioactivos beneficiosos para la salud (Campos et al., 2006). Los campesinos andinos suelen consumir toda la planta y de manera especial el tubérculo (Flores et al., 2003) del cual obtienen subproductos como harina y almidón. Los primeros procesamientos de la mashua como harina obtuvieron un producto picante, de olor fuerte y de aspecto amarillento catalogándose como poco satisfactorio (Grau et al., 2003). Ramallo (1999), estudio la composición de la harina de mashua, reportando $8 \%$ de proteína comparable con la harina de maíz y alto contenido energético $416 \mathrm{kcal} 100 \mathrm{~g}^{-1}$, sugiriéndolo como alimento para cerdos.

Por otro lado, el almidón se destacó por sus propiedades nutricionales (Grau et al., 2003), creando gran interés en los investigadores. La mashua contiene 41.35\% (BS) de almidón en el tubérculo, con un 27.44\% (BS) de amilosa (Valcárcel-Yamani et al., 2013). El almidón de mashua presenta gránulos más pequeños comparados con tubérculos como oca y ulluco, está compuesto de 2-3 granos heterogéneos (Surco, 2004). Su forma puede llegar a ser ovoide, esférico y truncados con tamaños de 4.39 y $16.29 \mu \mathrm{m}$ de longitud y 4.07 y $13.09 \mu \mathrm{m}$ de diámetro (Valcárcel-Yamani et al., 2013).

Según Valcárcel-Yamani et al. (2013) el almidón de tubérculos andinos como oca, ulluco y mashua se consideran de importancia en la industria alimentaria para la elaboración de productos de fácil cocción, alta viscosidad y baja estabilidad a la refrigeración, pero a diferencia de la oca y ulluco la mashua se destaca por su alta digestibilidad al poseer gránulos de tamaño pequeño.

La forma y tamaño de los gránulos de almidón de mashua ha sido discutida por varios investigadores; sin embargo, aún no se tiene conocimiento de investigaciones recientes sobre la morfología de la harina y proteína de mashua, la presente investigación tuvo como objetivo caracterizar morfométricamente el almidón, harina y proteína de cuatro muestras vegetales de mashua y buscar sus diferencias y similitudes con otros cultivos similares.

\section{Material vegetal}

Los tubérculos de cuatro genotipos de mashua (T. tuberosum) fueron recolectados del banco de germoplasma de la Facultad de Ciencias Agropecuarias de la Universidad Técnica de Ambato. Los genotipos fueron cultivados y cosechados en 2018; a partir, de cuatro accesiones de mashua de 
diferentes procedencias geográficas del Ecuador: el genotipo amarilla (MA) de la provincia de Tungurahua, verde amarilla (MVA) y poza rondador (MPR) en la provincia de Chimborazo y blanca (MB) de la provincia de Cotopaxi, estos corresponden a nombres vulgares adquiridos por fuentes locales de campesinos (Valle-Parra et al., 2018).

Los tubérculos se seleccionaron por su tamaño uniforme y sin magulladuras. Extracción de almidón de mashua. La extracción de almidón se realizó cuatro días después de la cosecha, empleando los métodos descritos por Torruco-Uco y Betancur-Ancona (2007), con ligeras modificaciones.

Los tubérculos fueron lavados y cepillados hasta eliminar toda impureza (tierra, hojas, raíces) y luego cortados en cubos de aproximadamente $3 \mathrm{~cm}$ por cada lado. Los cubos fueron triturados en una licuadora con agua destilada en una relación 1:2(p/v) durante $3 \mathrm{~min}$. La suspensión resultante fue filtrada con una tela de muselina para eliminar la fibra y el filtrado se dejó sedimentar a $4{ }^{\circ} \mathrm{C}$ durante $4 \mathrm{~h}$ en un vaso de precipitación. El almidón fue separado del sobrenadante mediante centrifugación a $3000 \mathrm{rpm}$ durante 5 min (Melian, 2010) en una centrífuga Sorvall ST 8 (X-150 Swinging Bucket Rotor), el sobrenadante fue descartado.

El almidón obtenido fue re suspendido en agua y dejado en sedimentación, para luego filtrar como fue descrito previamente. Este procedimiento se repitió de 3-4 veces con agua destilada y una última vez se filtró en capa de algodón hasta obtener un almidón blanco y un translucido flotante. El almidón limpio fue secado en una estufa (Modell 100-800) durante $24 \mathrm{~h}$ a $37^{\circ} \mathrm{C}$, molido en un mortero y tamizado hasta obtener un polvo homogéneo. El almidón fue almacenado en frascos plásticos con cierre de tapa hermética y conservada a-20 ${ }^{\circ} \mathrm{C}$.

Microscopía electrónica de barrido. La morfología estructural del almidón, harina y proteína de mashua se estudió mediante un microscopio electrónico de barrido (MEB) (modelo Tescan Vega3) con un aumento de hasta 100.000X, las imágenes se realizaron trabajando a $20.0 \mathrm{keV}$ en alto vacío. Las muestras se prepararon y se fijaron en trozos de cinta de carbono de doble cara y se recubrieron con oro utilizando un dispositivo de recubrimiento por pulverización catódica SPI-Module.

Para la tabulación de datos se realizó mediciones aleatorias del diámetro mayor o longitudinal $(\mathrm{DM})$, diámetro menor o transversal $(\mathrm{Dm})$ y largo $(\mathrm{L})$ de micrografías de gránulos de almidón, harina y láminas de proteína. Análisis estadístico. Para el análisis estadístico se utilizó el programa InfoStat versión 2008, mediante el uso de estadística descriptiva, con prueba de Tukey para determinar diferencias significativas entre promedios. En la Figura 1 se detalla la morfología de gránulos de almidón y muestras liofilizadas de harina y proteína de cuatro genotipos de mashua.

En la primera columna se observa micrografías de harina destacándose la forma ovalada y esférica en los genotipos MB, MA y MPR mientras que en el genotipo MVA predomina la forma ovalada, además en todas las muestras de harina se nota la presencia de material particulado y la presencia de láminas que podría corresponder a proteína. Todas las muestras de harina presentan superficie de apariencia lisa como los gránulos de almidón de papa (Solanum tuberosum) (Zhou et al., 2013), con algunas fisuras similares a la maca (Zhang et al., 2017) excepto en los gránulos de harina de MA donde se observan protuberancias y pequeños surcos parecidos a los gránulos de maíz (Singh et al., 2003). El tamaño de los gránulos de MB y MVA no presentan diferencias significativas a lo contrario de los genotipos MA y MPR (Cuadro 1). 
Cuadro 1. Tamaño y forma de los gránulos de almidón, harina y láminas de proteína de cuatro genotipos de mashua.

\begin{tabular}{|c|c|c|c|c|c|c|c|c|}
\hline \multirow[b]{2}{*}{ Genotipos } & \multicolumn{3}{|c|}{ Harina } & \multicolumn{3}{|c|}{ Almidón } & \multicolumn{2}{|c|}{ Proteína } \\
\hline & $\begin{array}{c}\text { Diámetro } \\
\text { mayor } \\
(\mu \mathrm{m})\end{array}$ & $\begin{array}{c}\text { Diámetro } \\
\text { menor } \\
(\mu \mathrm{m})\end{array}$ & Forma & $\begin{array}{c}\text { Diámetro } \\
\text { mayor } \\
(\mu \mathrm{m})\end{array}$ & $\begin{array}{l}\text { Diámetro } \\
\text { menor } \\
(\mu \mathrm{m})\end{array}$ & Forma & $\begin{array}{l}\text { Longitud } \\
\qquad(\mu \mathrm{m})\end{array}$ & Forma \\
\hline $\begin{array}{l}\text { Amarilla } \\
\text { (MA) }\end{array}$ & $\begin{array}{l}6.4^{\mathrm{a}} \pm 2.3 \\
(2.8-11.2)\end{array}$ & $\begin{array}{l}5^{\mathrm{a}} \pm 1.5 \\
(2.5-8)\end{array}$ & Ovalada & $\begin{array}{c}7.1^{\mathrm{a}} \pm 2.4 \\
(3.2-12.3)\end{array}$ & $\begin{array}{l}6.1^{a} \pm 1.6 \\
(3.2-9.1)\end{array}$ & $\begin{array}{c}\text { Ovalada } \\
\text { y } \\
\text { esférica }\end{array}$ & $\begin{array}{c}205.8^{\mathrm{a}} \pm 60.2 \\
(139.5-257)\end{array}$ & $\begin{array}{l}\text { Poligonal } \\
\text { asimétrica } \\
\text { aplanada }\end{array}$ \\
\hline $\begin{array}{l}\text { Blanca } \\
\text { (MB) }\end{array}$ & $\begin{array}{c}9.4^{\mathrm{ab}} \pm 2.6 \\
(4-14.1)\end{array}$ & $\begin{array}{l}8.6^{\mathrm{ab}} \pm 2.3 \\
(3.5-12.6)\end{array}$ & Ovalada & $\begin{array}{l}18^{\mathrm{b}} \pm 5.4 \\
(6.7-29)\end{array}$ & $\begin{array}{c}16.3^{\mathrm{b}} \pm 4.4 \\
(6.7-24)\end{array}$ & $\begin{array}{c}\text { Ovalada } \\
\text { y } \\
\text { esférica }\end{array}$ & $\begin{array}{c}223.7^{\mathrm{a}} \pm 110.9 \\
(125-469.7)\end{array}$ & $\begin{array}{c}\text { Poligonal } \\
\text { asimétrica } \\
\text { aplanada }\end{array}$ \\
\hline $\begin{array}{l}\text { Verde } \\
\text { Amarilla } \\
\text { (MVA) }\end{array}$ & $\begin{array}{c}8.3^{\mathrm{ab}} \pm 3.1 \\
(3.6-12)\end{array}$ & $\begin{array}{c}6.9^{\mathrm{ab}} \pm 2.5 \\
(2.7-9.3)\end{array}$ & Ovalada & $\begin{array}{c}8.3^{\mathrm{a}} \pm 2.4 \\
(3.8-11.5)\end{array}$ & $\begin{array}{c}7.3^{\mathrm{a}} \pm 2 \\
(3.8-11.1)\end{array}$ & $\begin{array}{c}\text { Ovalada } \\
\text { y } \\
\text { esférica }\end{array}$ & $\begin{array}{c}129.7^{\mathrm{a}} \pm 35.2 \\
(89-151)\end{array}$ & $\begin{array}{l}\text { Poligonal } \\
\text { asimétrica } \\
\text { aplanada }\end{array}$ \\
\hline $\begin{array}{l}\text { Poza } \\
\text { Rondador } \\
\text { (MPR) }\end{array}$ & $\begin{array}{c}9.9^{\mathrm{b}} \pm 4.9 \\
(5-21.7)\end{array}$ & $\begin{array}{l}9.1^{\mathrm{b}} \pm 4.9 \\
(4.1-21.7)\end{array}$ & $\begin{array}{c}\text { Ovalada } \\
\text { y } \\
\text { esférica }\end{array}$ & $\begin{array}{c}7^{\mathrm{a}} \pm 2.2 \\
(3.6-10.2)\end{array}$ & $\begin{array}{l}6.5^{\mathrm{a}} \pm 2.2 \\
(3.6-9.5)\end{array}$ & $\begin{array}{c}\text { Ovalada } \\
\text { y } \\
\text { esférica }\end{array}$ & $\begin{array}{c}237^{\mathrm{a}} \pm 52.4 \\
(200-297)\end{array}$ & $\begin{array}{l}\text { Poligonal } \\
\text { asimétrica } \\
\text { aplanada }\end{array}$ \\
\hline
\end{tabular}

$\overline{\mathrm{a}-\mathrm{b}}=$ superíndices distintos en la misma fila indican diferencias significativas $(p>0.05)$. Valores entre paréntesis indican los valores máximos y mínimos observados.

Los gránulos de harina de MA tienen diámetros promedio de $6.4 \mu \mathrm{m}$ (DM) y $5 \mu \mathrm{m}$ (Dm), el genotipo MB reporta $9.4 \mu \mathrm{m}(\mathrm{DM})$ y $8.6 \mu \mathrm{m}(\mathrm{Dm})$, el genotipo MVA tiene tamaños de $8.3 \mu \mathrm{m}$ (DM) y $6.9 \mu \mathrm{m}(\mathrm{Dm})$ y los gránulos de harina de MPR reporta $9.9 \mu \mathrm{m}(\mathrm{DM})$ y $9.1 \mu \mathrm{m}(\mathrm{Dm})$. Las micrografías de los gránulos de almidón se muestran en la segunda columna de la Figura 1. Los gránulos de almidón de los cuatro genotipos tienen una morfología donde predomina las estructuras ovaladas y esféricas y con menor participación las formas esféricas-truncadas.

Estas similitudes se exponen en los cuatro genotipos, resultados que concuerdan con otros estudios, como las micrografías de gránulos de mashua amarilla reportado por Valcárcel-Yamani et al. (2013) y otros tubérculos como makal (Xanthosoma yucatanensis) (Torruco-Uco y BetancurAncona, 2007) y raíces de arrurruz (Maranta arundinacea) (Peroni et al., 2006).

El tamaño de los gránulos de almidón es semejante entre los genotipos MA, MVA y MPR, mientras que el genotipo MB se diferencia por tener los gránulos más grandes (Cuadro 1). Los diámetros mayores de los gránulos tienen promedios desde los $18 \mu \mathrm{m}$ para el genotipo $\mathrm{MB}, 7.1 \mu \mathrm{m}$ en MA, $8.3 \mu \mathrm{m}$ en MVA y $7 \mu \mathrm{m}$ en MPR y diámetros menores de $6.1,16.3,7.3$ y $6.5 \mu \mathrm{m}$ respectivamente.

Estos valores son similares al tamaño de los gránulos reportados en genotipos de mashua amarilla con 4.39 y $16.29 \mu \mathrm{m}(\mathrm{DM})$ y 4.07 y $13.09 \mu \mathrm{m}$ de (Dm) (Valcárcel-Yamani et al., 2013). También, se han notificado otros valores similares como la maca (Lepidium meyenii Walpers) $(9 \mu \mathrm{m})$, mandioca (Manihot esculenta) $(12.9 \mu \mathrm{m})$ y makal $(12.4 \mu \mathrm{m})$ (Charles et al., 2005; HernándezMedina et al., 2008; Torruco-Uco y Betancur-Ancona, 2007; Zhang et al., 2017). 


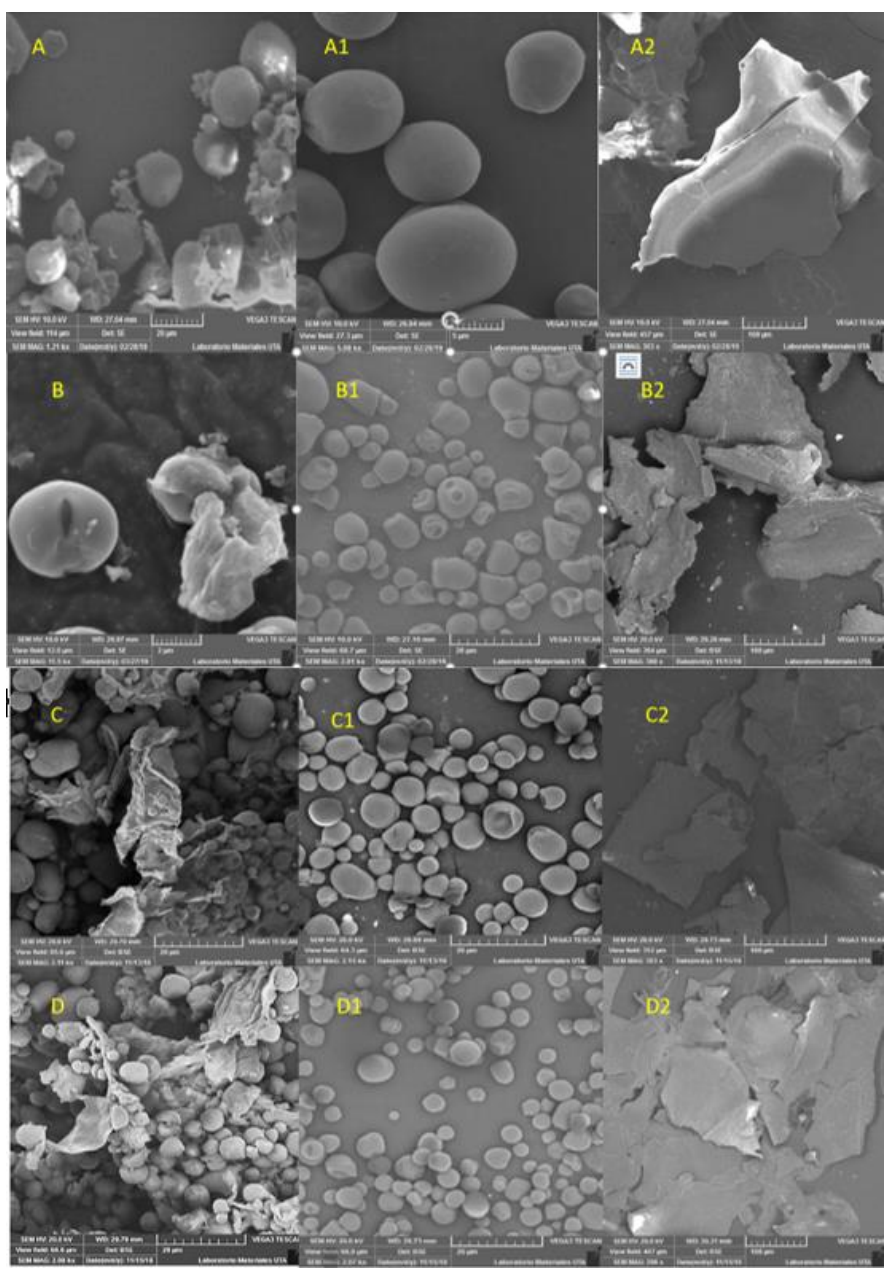

Figura 1. Micrografías electrónicas (SEM) de izquierda a derecha: harina, almidón y proteina de mashua genotipo MB (A-A2); MA (B-B2); MVA (C-C2); y MPR (D-D2) con amplificacion de $100000 \mathrm{X}$.

Las diferencias en tamaño y forma de los gránulos pueden atribuirse a varios factores, uno de ellos la agricultura, investigadores exponen que los cultivos andinos en el transcurso del tiempo han sufrido cambios en la domesticación y reproducción lo que sugiere una influencia sobre las características morfológicas y tamaño del gránulo del almidón (King y Gershoff, 1987; Flores et al., 2003); sin embargo, con los avances modernos hoy se cree que el tamaño del gránulo podría estar relacionado con las prácticas agrícolas (Torres et al., 2011).

Así también, ciertos estudios atribuyen los resultados al origen biológico, la bioquímica del cloroplasto y la fisiología de la planta (Singh et al., 2003). Mientras que, otros autores sostienen que la morfología y tamaño de los gránulos de almidón dependen de la genética de la planta, además, de las estructuras membranosas y las características físicas de los plástidos (Lindeboom et al., 2004).

La última columna reporta micrografías de proteína de los cuatro genotipos de mashua (Figura 1). La forma de la proteína es algo peculiar ya que no son esféricas ni ovaladas sino estructuras laminares con superficie quebradiza y forma poligonal asimétrica. Estas láminas tienen longitudes 
promedio distintas que van desde los 130, 221, 224 y $237 \mu \mathrm{m}$ (MVA, MA, MB y MPR, respectivamente) (Cuadro 1), su forma se asemeja a la albumina de guisante de playa (Lathyrus maritimus L.) con topografía de placa y superficie lisa (Chavan et al., 2001) y la albumina de frejol (Phaseolus vulgaris L.) variedad Great Northern con forma de vara (Sathe y Salunkhe, 1981). Investigaciones pasadas han indicado que las características topográficas de las proteínas podrían intervenir en las propiedades fisicoquímicas y funcionales del almidón (Chavan et al., 2001), pero al estar en bajos niveles no tendrían efectos negativos según lo expone Hoover (2001).

\section{Conclusiones}

El estudio de la morfología del almidón mostró formas ovaladas y esféricas similares a los gránulos de harina, pero diferentes al liofilizado de proteínas con estructuras laminares con forma poligonal asimétrica, en lo que se refiere al tamaño de los gránulos de almidón y harina, se observó que los genotipos MB y MPR fueron los que destacaron en mayor tamaño respectivamente, mientras que las láminas de proteína presentaron diferencias significativas siendo las más grandes la del genotipo MPR.

\section{Agradecimientos}

Las autoras desean expresar el más profundo agradecimiento a la ingeniera Cristian Pérez Coordinadora del laboratorio de Materiales de la Facultad de Civil y Mecánica por su valioso apoyo con el uso del microscopio electrónico de barrido.

\section{Literatura citada}

Torres, F. G.; Troncoso, O. P.; Díaz, D. A. and Amaya, E.; 2011. Morphological and thermal characterization of native starches from Andean crops. Starch-Starke. 63(6):381-389. https://doi.org/10.1002/star.201000155.

Barrera, V.; Espinosa, P.; Tapia, C.; Monteros, A. y Valverde, F. 2004. Caracterización de las raíces y los tubérculos andinos en la ecoregión andina del Ecuador (Capítulo 1). In: Barrera, V.; Tapia, C. y Monteros, A. (Ed.). Raíces y tubérculos andinos: alternativas para la conservación y uso sostenible en el Ecuador. Serie: conservación y uso de la biodiversidad de raíces y tubérculos andinos: una década de investigación para el desarrollo (1993-2003). Instituto Nacional Autónomo de Investigaciones Agropecuarias- Centro Internacional de la Papa, Agencia Suiza para el Desarrollo y la Cooperación. Quito, Ecuador-Lima, Perú. No. 4. 3-30 pp.

Campos, D.; Noratto, G.; Chirinos, R.; Arbizu, C.; Roca, W. and Luis, C. Z. 2006. Antioxidant capacity and secondary metabolites in four species of Andean tuber crops: native potato (Solanum sp.), mashua (Tropaeolum tuberosum Ruiz \& Pavón), Oca (Oxalis tuberosa Molina) and ulluco (Ullucus tuberosus Caldas). J. Sci. Food Agric. 86(2):1481-1488. https://doi.org/10.1002/jsfa.

Charles, A. L.; Chang, Y. H.; Ko, W. C.; Sriroth, K. and Huang, T. C. 2005. Influence of amylopectin structure and amylose content on the gelling properties of five cultivars of cassava starches. J. Agric. Food Chem. 53(7):2717-2725. https://doi.org/10.1021/ jf048376+. 
Chavan, U. D.; McKenzie, D. B. and Shahidi, F. 2001. Protein classification of beach pea (Lathyrus maritimus L.). Food Chem. 75(2):145-153. https://doi.org/10.1016/S03088146(01)00122-4.

Flores, H. E.; Walker, T. S.; Guimarães, R. L.; Bais, H. P. and Vivanco, J. M. 2003. Andean root and tuber crops: Underground rainbows. HortScience. 38(2):161-167. https://doi.org/ 10.21273/hortsci.38.2.161.

Grau, A., Ortega Dueñas, R., Nieto Cabrera, C., y Hermann, M. 2003. Mashua Tropaeolum tuberosum Ruíz \& Pav. Promoting the conservation and use of underutilized and neglected crops.1ra Ed. Lima-Peru y Roma-Italia. International Potato Center/International Plant Genetic Resources Institute. 54 p. https://www.bioversityinternational.org/fileadmin/_ migrated/uploads/tx_news/Mashua_Tropaeolum_tuberosum-Ru\%c3\%adz_amp_Pav.880.pdf.

Hernández-Medina, M.; Torruco-Uco, J. G.; Chel-Guerrero, L. and Betancur-Ancona, D. 2008. Caracterización fisicoquímica de almidones de tubérculos cultivados en Yucatán, México. Ciencia y Tecnología Alimentos Campinas. 28(3):718-726.

Hoover, R. 2001. Composition, molecular structure, and physicochemical properties of tuber and root starches: a review. Carbohydrate Polymers. 45(3):253-267.

King, S. R. and Gershoff, S. N. 1987. Nutritional evaluation of three underexploited andean tubers:Oxalis tuberosa (Oxalidaceae), Ullucus tuberosus (Basellaceae), and Tropaeolum tuberosum (Tropaeolaceae). Economic Botany. 41(4):503-511. https://doi.org/10.1007/ BF02908144.

Lim, T. K. 2016. Edible medicinal and non medicinal plants. Dordrecht, Alemania. Springer. 12:94-102. https://doi.org/10.1007/978-94-017-9511-1.

Lindeboom, N.; Chang, P. R. and Tyler, R. T. 2004. Analytical, biochemical and physicochemical aspects of starch granule size, with emphasis on small granule starches: a review. StarchStärke. 56(34):89-99. https://doi.org/10.1002/star.200300218.

Manrique, I.; Arbizu, C.; Vivanco, F.; Gonzales, R.; Ramírez, C.; Chávez, O. and Ellis, D. 2013. Tropaeolum tuberosum Ruíz \& Pav. Colección de germoplasma de mashua conservada en el Centro Internacional de la Papa (CIP). Centro internacional de la Papa. $1^{\text {ra. }}$ Ed. Lima, Perú. 122 p.

Melian, D. 2010. Ensayo comparativo de dos metodologías de extracción de almidón de papa usando muestras de diez variedades nativas de Chiloé y dos Daniela Elizabeth Melian Subiabre. Universidad Austral de Chile.

National Research Council. 1989. Lost Crops of the Incas: Little-Known Plants of the Andes with Promise for Worldwide Cultivation. In: National Academy Press. $1^{\text {ra. }}$ ed. Washington, DC. 66-73 p. https://doi.org/10.17226/1398.

Peroni, F. H. G.; Rocha, T. S. and Franco, C. M. L. 2006. Some structural and physicochemical characteristics of tuber and root starches. Food Sci.Technol. Inter. 12(6):505-513. https://doi.org/10.1177/1082013206073045.

Pissard, A.; Arbizu, C.; Ghislain, M. and Bertin, P. 2008. Influence of geographical provenance on the genetic structure and diversity of the vegetatively propagated andean tuber crop, Mashua (Tropaeolum tuberosum), highlighted by intersimple sequence repeat markers and multivariate analysis methods. Inter. J. Plant Sci. 169(9):1248-1260. https://doi.org/10.1086/591979.

Ramallo, R. 1999. Diseño de una planta procesadora de harina de isaño como base de la alimentación porcina. Universidad Privada Boliviana. Cochabamba, Bolivia. 
Sathe, S. K. and Salunkhe, D. K. 1981. Functional properties of the great northern bean (Phaseolus vulgaris L.) proteins: emulsion, foaming, viscosity, and gelation properties. J. Food Sci. 46(1):71-81. https://doi.org/10.1111/j.1365-2621.1981.tb14533.x.

Singh, N.; Singh, J.; Kaur, L.; Singh, N. and Singh, B. 2003. Morphological, thermal and rheological properties of starches from different botanical sources. Food Chem. 81(2):219-231. https://doi.org/10.1016/S0308-8146(02)00416-8.

Surco, F. 2004. Caracterización de almidones aislados de tuberculos andinos: mashua (Tropaeolum tuberosum), Oca (Oxalis tuberosa), Olluco (Ullucus tuberosus) para su aplicación tecnológica. 1-55 pp. http://cybertesis.unmsm.edu.pe/handle/cybertesis/2588.

Torruco-Uco, J. and Betancur-Ancona, D. 2007. Physicochemical and functional properties of makal (Xanthosoma yucatanensis) starch. Food Chem. 101(4):1319-1326. https://doi.org/10.1016/j.foodchem.2006.03.047.

Valcárcel-Yamani, B.; Rondán-Sanabria, G. G. and Finardi-Filho, F. 2013. The physical, chemical and functional characterization of starches from andean tubers: Oca (Oxalis tuberosa molina), olluco (Ullucus tuberosus caldas) and mashua (Tropaeolum tuberosum Ruiz \& Pavón). Brazilian J. Pharmaceutical Sci. 49(3):453-464. https://doi.org/10.1590/S198482502013000300007.

Valle-Parra, M.; Pomboza-Tamaquiza, P.; Buenaño-Sánchez, M.; Guevara-Freire, D.; ChasiVizuete, P.; Vásquez, C. and Pérez-Salinas, M. 2018. Morphology, phenology, nutrients and yield of six accessions of Tropaeolum tuberosum Ruiz y Pav (Mashua). Trop. Subtrop. Agroecosystems. 21(1):131-139.

Zhang, L.; Li, G.; Wang, S.; Yao, W. and Zhu, F. 2017. Physicochemical properties of maca starch. Food Chem. 218(1):56-63. https://doi.org/10.1016/j.foodchem.2016.08.123.

Zhou, Q.; Shi, W.; Meng, X. and Liu, Y. 2013. Studies on the morphological, crystalline, thermal properties of an underutilized starch from yam Dioscoreae zingiberensis C. H. Wright. Starch/Staerke. 65(1-2):123-133. https://doi.org/10.1002/star.201200058. 